\title{
Tingkat Kelimpahan Makrozoobenthos di Padang Lamun Perairan Telaga dan Pulau Bengkoang, Karimunjawa
}

\author{
Sri Wahyu Ningsih*, Wilis Ari Setyati dan Nur Taufiq-Spj \\ Departemen IImu Kelautan, Fakultas Perikanan dan IImu Kelautan, Universitas Diponegoro \\ JI. Prof. H. Soedarto S.H, Tembalang, Semarang, Jawa Tengah 50275 Indonesia \\ ${ }^{*}$ Corresponding author, e-mail : nsriwahyu43@gmail.com
}

\begin{abstract}
ABSTRAK: Taman Nasional Karimunjawa merupakan daerah perairan yang mempunyai ekosistem laut yang masih lengkap dan asri. Padang lamun merupakan salah satu ekosistem pendukung di wilayah pesisir yang pada umumnya terdapat di daerah tropis dan memiliki peranan penting di perairan. Makrozoobenthos adalah salah satu hewan yang berasosiasi dengan padang lamun yang memanfaatkan padang lamun sebagai tempat mencari makan dan tempat memijah. Tujuan penelitian tentang kelimpahan makrozoobenthos di Perairan Telaga dan Pulau Bengkoang diperlukan untuk mengetahui perbedaan serta pengaruh fisika-kimia terhadap populasi lamun dan makrozoobenthos untuk mengindikasikan kualitas suatu perairan. Penelitian ini dilaksanakan pada bulan Oktober 2019dengan menggunakan metodepurposivesampling yang dapat mewakili seluruh kawasan. Hasil komposisi makrozoobenthos yang di temukan pada masingmasing stasiun mempunyai perbedaan yang cukup signifikan. Jumlah makrozoobenthos Perairan Telaga terdapat sebanyak 42 individu makrozoobenthos yang ditemukan, sedangkan di Pulau Bengkoang terdapat sebanyak 55 individu makrozoobenthos yang ditemukan. Jumlah makrozoobenthos yang di temukan pada Perairan Telaga line 1 sebanyak 11 individu, line 2 sebanyak 15 individu dan line 3 sebanyak 14 individu. Jumlah makrozooobenthos yang di temukan pada Pulau Bengkoang line 1 sebanyak 19 individu, line 2 sebanyak 17 individu dan line 3 sebanyak 19 individu.Makrozoobenthos yang ditemukan pada masing-masing stasiun penelitian mempunyai hubungan yang kuat antara kelimpahan makrozoobenthos dengan tutupan lamun serta dengan bahan organik.
\end{abstract}

Kata kunci: Makrozoobenthos, Lamun, Perairan Telaga, Pulau Bengkoang

\section{Makrozoobenthos Abundance Level In Padang Lagang Telaga Waters And Bengkoang Island, Karimunjawa National Park}

\begin{abstract}
Karimunjawa National Park is a watershed area that has a complete and beautiful marine ecosystem. Seagrass beds are one of the supporting ecosystems in coastal areas which are generally found in the tropics and have an important role in the waters. Macrozoobenthos is one of the animals associated with seagrass that uses seagrass as a place to find food and spawning grounds. The purpose of research on the abundance of macrozoobenthos in Telaga Waters and Bengkoang Island is needed to determine the differences and the influence of physics-chemistry on seagrass populations and macrozoobenthos to indicate the quality of a waters. This research was conducted in October 2019 using a purposive sampling method that can represent the entire region. The results of the macrozoobenthos composition found at each station have quite significant differences. The number of macrozoobenthos of Lake Ponds were 42 macrozoobenthos individuals found, while in Bengkoang Island there were 55 macrozoobenthos individuals found. The number of macrozoobenthos found in Telaga Line 1 is 11 individuals, line 2 is 15 individuals and line 3 is 14 individuals. The number of macrozooobenthos found on Bengkoang Island line 1 were 19 individuals, line 2 were 17 individuals and line 3 were 19 individuals. Macrozoobenthos found at each research station have a strong relationship between abundance of macrozoobenthos with seagrass cover and with organic matter.
\end{abstract}

Keywords: Macrozoobentos, Seagrass, Telaga Waters, Bengkoang Island 


\section{PENDAHULUAN}

Taman Nasional Karimunjawa memiliki luasan padang lamun yang terdapat hampir di setiap garis pantainya. Ekosistem padang lamun merupakan salah satu ekosistem pendukung di wilayah pesisir yang pada umumnya terdapat di daerah tropis dan memiliki peranan penting di perairan.Padang lamun merupakan salah satu komponen ekosistem laut yang mempunyai siklus nutrisi, penyerapan karbon, struktur rantai makanan dan jasa ekosistem yang bernilai tinggi serta dapat meningkatkan kualitas air (Effrosynidis, Arampatzis, \& Sylaios 2019; Al-Wedaei, K., et al, 2011). Daerah padang lamun banyak memberikan manfaat bagi biota bentik khususnya epifauna yaitu sebagai sumber makanan, daerah asuhan dan tempat berlindung dari predator (Ristianti, 2014).Ekosistem lamun memainkan peran penting dalam menyediakan makanan dan perlindungan bagi ekosistem organisme yang hidup di dalam dan sekitar padang lamun (Asriani et al., 2019).

Makrozoobenthos merupakan salah satu organismeyang mempunyai ukuran lebih besar dari 1,0 mm (Arami, 2019). Ekosistem padang lamun yang rusak tidak hanya berdampak terhadap makrozoobenthos tetapi berdampak dengan tingkat kesuburan perairan tersebut. Biota yang banyak dijumpai pada daerah padang lamun yaitu dari kelas Gastropoda, Bivalvia, Echinoidea, dan Holothuroidea. Makrozoobenthos selain mempunyai ketergantungan terhadap nutrien dari lamun juga membutuhkan nutrient bahan organik yang berasal dari sedimen dasar perairan. Makrozoobenthos dianggap sebagai indikator untuk menguji status lingkungan dan sangat berguna untuk deteksi jangka pendek fluktuasi faktor abiotik karena variabilitas tinggi mereka sulit untuk diukur secara langsung (Warzocha et al., 2018; Rachman, Priyono \& Mardianto, 2016).Tinggi rendahnya bahan organik berpengaruh terhadap kelimpahan dan keberadaan makrozoobenthos (Ruswahyuni, 2010; Muliawan, Irma \& Sofyatuddin, 2016), serta perubahan kualitas lingkungan berpengaruh terhadap komposisi dan kelimpahan biota (Tussa'diyyah, Purwoko \& Kamal, 2018).

Penelitian yang terdahulu sudah dilakukan pada beberapa pulau di Karimunjawa, tetapi belum adanya penelitian antara dua stasiun yang berbeda. Perairan Telaga berada di bagian utara Pulau Kemujan yang berada dekat dengan pemukiman, sedangkan Pulau Bengkoang merupakan pulau tidak berpenghuni yang mempunyai ekosistem laut yang masih asri. Mengingat belum adanya penelitian tersebut maka dilakukan penelitian untuk mengetahui kelimpahan makrozoobenthos di padang lamun Perairan Telaga dan Pulau Bengkoang, Taman Nasional Karimunjawa, Kabupaten Jepara. Tujuan penelitian ini mengetahui adanya kelimpahan makrozoobenthos yang terdapat di ekosistem padang lamun, mengetahui jumlah kandungan bahan organik pada substrat padang lamun dan mengetahui korelasi bahan organik dengan kelimpahan makrozoobenthos.

\section{MATERI DAN METODE}

Penelitian ini dilakukan pada bulan oktober 2019 di Perairan Telaga dan Pulau Bengkoang, Taman Nasional Karimunjawa. Metode pendataan lamun dan sampling makrozoobenthos menggunakan metode pusposive sampling yang mengacu ke metode seagrasswatch. Penentuan lokasi stasiun dengan menarik tiga transek paralel dengan jarak 25 $\mathrm{m}$ antar transek dan tegak lurus dengan garis pantai. Identfikasi dilakukan setiap $5 \mathrm{~m}$ dengan transek kuadrat persegi yang berukuran $50 \mathrm{~cm} \times 50 \mathrm{~cm}$ dimulai dari $0 \mathrm{~m}$ hingga $50 \mathrm{~m}$ ke arah laut lepas dengan total ada 11 kuadrat.

Sampling makrozoobenthos menggunakan modifikasi metode dari Indrawan, Yusup \& Ulinuha (2016), tiga transek tegak lurus pantai dengan jarak tiap transek $25 \mathrm{~m}$ dan tiap transek dibagi menjadi 3 titik sampel $(0 \mathrm{~m}, 25 \mathrm{~m}, 50 \mathrm{~m})$. Pengambilan data sampel pada tiap transek menggunakan kuadrat $1 \mathrm{~m} \times 1 \mathrm{~m}$ yang dilakukan pada 2 stasiun yaitu di Pulau Kemujan dan di Pulau Bengkoang. Pengambilan sampel makrozoobenthos yang berada pada permukaan substrat, diambil secara langsung. Makrozoobenthos yang didapat langsung diawetkan dengan menggunakan campuran formalin $10 \%$ dan rosebangle. Identifikasi makrozoobenthos dikukan di Laboratorium dan hitung jumlah organisme yang ditemukan. 
Indeks Kepadatan, untuk menentukan kepadatan makrozoobenthos di lokasi penelitian, analisis data yang digunakan adalah indeks Shannon-Wienner (Arami, 2019). Menurut Arami (2019), indeks keanekaragaman jenis adalah indeks keanekaragaman yang menunjukkan banyak tidaknya jenis dan individu yang ditemukan pada suatu perairan. Arami (2019), menyatakan bahwa indeks keseragaman adalah indeks yang menunjukkan pola sebaran biota, yaitu merata atau tidak. Menurut Arami (2019), menyatakan bahwa indeks dominansi Simpson dapat digunakan untuk mengetahui terjadinya dominansi jenis tertentu diperairan.

Hubungan antara kelimpahan makrozoobenthos dengan tutupan lamun dan bahan organik menggunakan analisa regresi korelasi sederhana pada Microsoft Excel. Variabel yang terlihat di dalamnya ada dua yakni tutupan lamun $(X)$ dan variabel kelimpahan makrozoobenthos $(Y)$ dan hubungan bahan organik ( $\mathrm{Y}$ ) dan kelimpahan makrozoobenthos (X). Menurut Ruswahyuni (2010), pedoman untuk memberikan interpretasi koofisien korelasi adalah sebagai berikut : 0,00 $-0,199$ = sangat rendah; $0,20-0,399=$ rendah; $0,40-0,599=$ sedang; $0,60-0,799=$ kuat; $0,80-$ $1,00=$ sangat kuat

\section{HASIL DAN PEMBAHASAN}

Komposisi makrozoobenthos yang ditemukan selama penelitian bahwa di Perairan Telaga ditemukan makrozoobenthos yang terdiri dari 4 kelas yaitu kelas Gastropoda, Bivalvia, Echinoidea dan Holothuroidea. Komposisi jumlah total jenis makrozoobenthos yang ditemukan selama penelitian yang terdiri dari kelas Gastropoda 38 jenis, Holothuroidea 2 jenis Bivalvia 1 jenis, Echinoidea 1 jenis dan. Sedangkan, di Pulau Bengkoang ditemukan makrozoobenthos yang terdiri dari 4 kelas yaitu kelas Gastropoda, Bivalvia, Holothuroidea, Malacostraca dan Echinoidea. Komposisi jumlah total jenis makrozoobenthos yang ditemukan selama penelitian yang terdiri dari kelas Gastropoda 18 jenis, Bivalvia 26 jenis, Holothuroidea 1 jenis, Malacostraca 1 jenis dan Echinoidea 2 jenis. Kelas Gastropoda merupakan kelas yang banyak ditemukan di Perairan Telaga dan Pulau Bengkoang.

Tabel 1. Hasil Pengukuran Data Rajungan Jantan dan Betina

\begin{tabular}{|c|c|c|c|c|c|c|}
\hline \multirow{3}{*}{ No } & \multicolumn{6}{|c|}{ Kelimpahan (Ind/ha) } \\
\hline & \multicolumn{3}{|c|}{ Perairan Telaga } & \multicolumn{3}{|c|}{ Pulau Bengkoang } \\
\hline & Line 1 & Line 2 & Line 3 & Line 1 & Line 2 & Line 3 \\
\hline 1 & 12 & 20 & 12 & 4 & 4 & 12 \\
\hline 2 & 8 & 20 & 4 & 8 & 4 & 8 \\
\hline 3 & 8 & 28 & 4 & 8 & 4 & 4 \\
\hline 4 & 8 & - & 8 & 8 & 4 & 4 \\
\hline 5 & 4 & - & 16 & 4 & 4 & 4 \\
\hline 6 & 4 & - & 4 & 4 & 4 & 4 \\
\hline 7 & - & - & 4 & 4 & 28 & 32 \\
\hline 8 & - & - & 4 & 4 & 8 & 8 \\
\hline 9 & - & - & - & 4 & 8 & - \\
\hline 10 & - & - & - & 28 & - & - \\
\hline . & 44 & 68 & 56 & 76 & 68 & 76 \\
\hline Rata-rata & 7,33 & 22,66 & 7 & 7,6 & 7,55 & 9,5 \\
\hline
\end{tabular}

Hubungan makrozoobenthos dengan bahan organik berdasarkan nilai koefisien $r$ sebesar 0,4849 diasumsikan bahwa bahan organik mempunyai pengaruh yang sedang terhadap kelimpahan makrozoobenthos di Perairan Telaga, sedangkan nilai koefisien $r$ di Pulau Bengkoang yaitu 0,9926 diasumsikan bahwa bahan organik mempunyai pengaruh yang kuat terhadap kelimpahan makrozoobenthos. Hasil analisis regresi sederhana kelimpahan makrozoobenthos dengan bahan organik di Perairan Telaga menunjukkan nilai koefisien determinasi (R2) sebesar 
0,2352 artinya $23,52 \%$ kelimpahan makrozoobenthos dipengaruhi oleh bahan organik dan $76,48 \%$ sisanya dipengaruhi oleh faktor lain, sedangkan nilai korelasi kelimpahan makrozoobenthos dengan bahan organik di Pulau Bengkoang menunjukkan nilai koefisien determinasi (R2) sebesar 0,9854 artinya 98,96\% kelimpahan makrozoobenthos di pengaruhi oleh bahan organik dan 1,46\% sisanya dipengaruhi oleh faktor lain. Persamaan regresi Perairan Telaga yaitu $y=-0,0007 x+0,06$ nilai negatif pada grafik menunjukkan hubungan terbalik yaitu semakin rendah kelimpahan makrobenthos maka semakin tinggi kandungan bahan organik, sedangkan persamaan regresi Pulau Bengkoang yaitu $y=0,0459 x-0,2491$ nilai positif pada grafik menunjukkan hubungan searah yaitu semakin tinggi kelimpahan maka semakin tinggi kandungan bahan organik. Pernyataan Ruswahyuni (2010), nilai positif menunjukan hubungan searah ( $x$ naik, maka y naik) dan nilai negative menunjukan hubungan terbalik ( $x$ naik, maka y turun). Sedimen yang kaya bahan organik sering didukung oleh melimpahnya organisme, termasuk juga epifauna karena bahan organik merupakan sumber makanan bagi biota laut yang hidup pada substrat dasar sehingga ketergatungannya terhadap bahan organik sangat kuat.

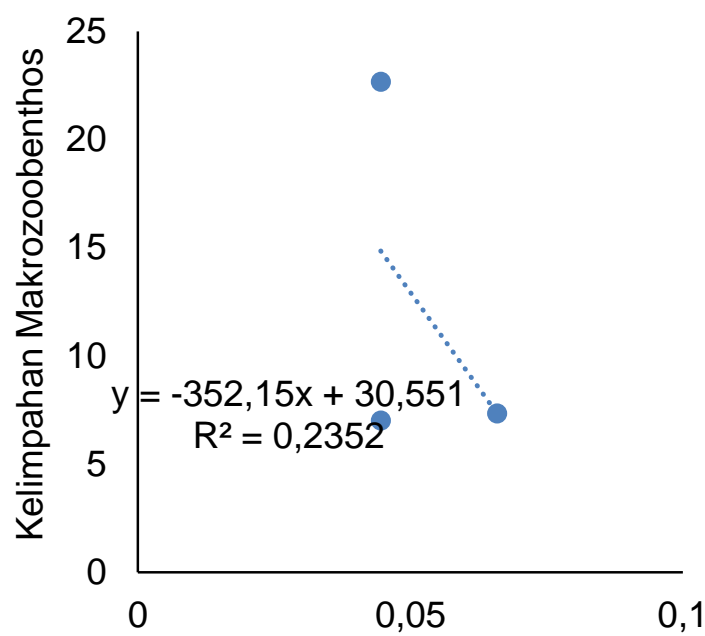

Bahan Organik

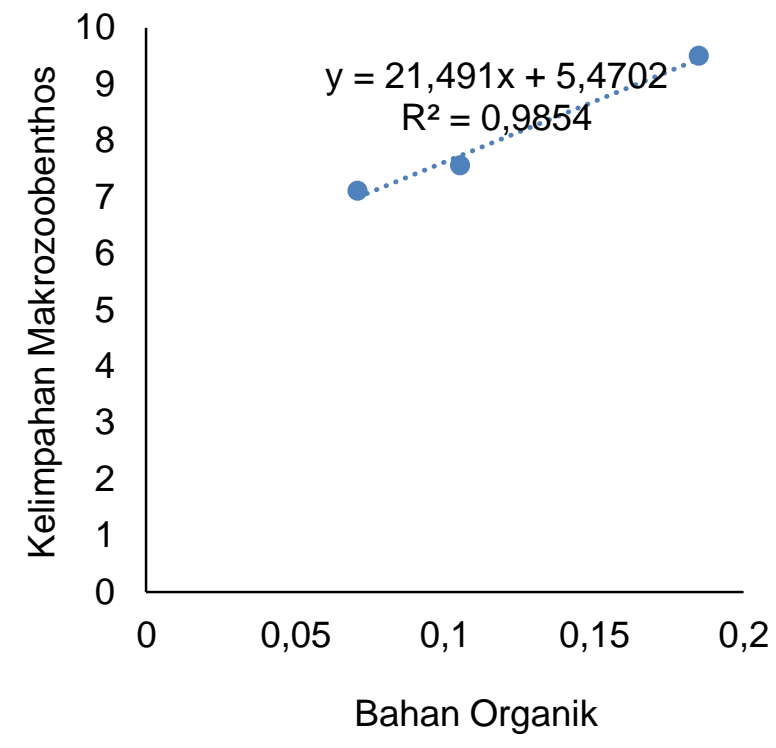

Pulau Bengkoang

Perairan Telaga

Gambar 1. Grafik Hubungan Kelimpahan Makrozoobenthos dengan Bahan Organik

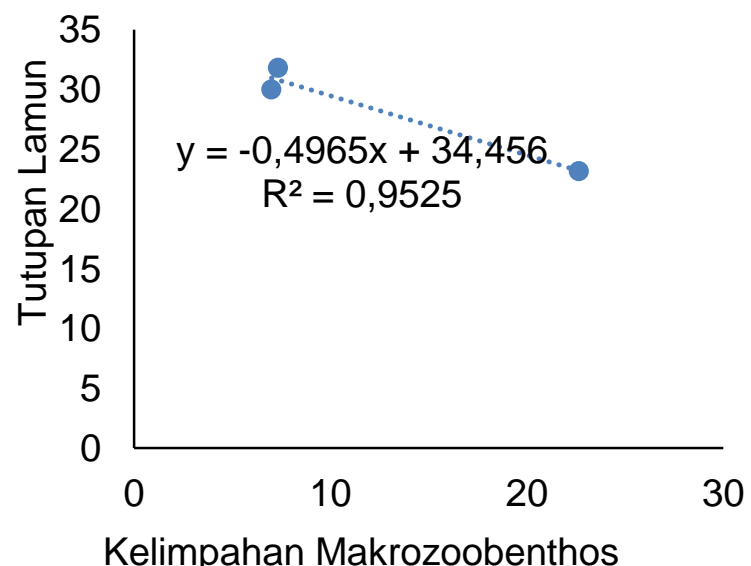

Perairan Telaga

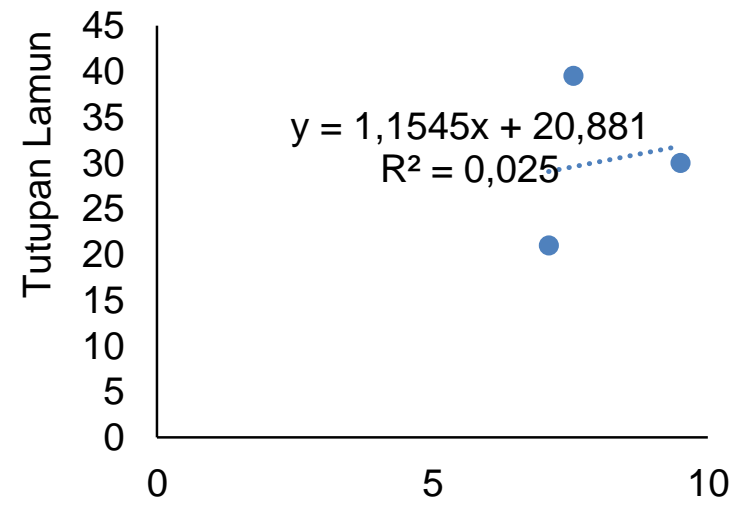

Kelimpahan Makrozoobenthos

Gambar 2. Grafik Hubungan Kelimpahan Makrozoobenthos dengan Tutupan Lamun 
Hubungan makrozoobenthos dengan tutupan lamun berdasarkan nilai koefisienrsebesar 0,9759 diasumsikan bahwa bahan organik mempunyai pengaruh yang kuat terhadap kelimpahan makrozoobenthos di Perairan Telaga, sedangkan nilai koefisien r di Pulau Bengkoang yaitu 0,1581 diasumsikan bahwa bahan organik mempunyai pengaruh yang rendah terhadap kelimpahan makrozoobenthos. Analisis regresi sederhana kelimpahan makrozoobenthos dengan tutupan lamun di Perairan Telaga menunjukkan nilai koefisien determinasi (R2) yaitu sebesar 0,9525 artinya 95,25\% kelimpahan makrozoobenthos di pengaruhi oleh tutupan lamun di Perairan Telaga dan $4,75 \%$ sisanya dipengaruhi oleh faktor lain, sedangkan nilai korelasi kelimpahan makrozoobenthos dengan tutupan lamun di Pulau Bengkoang nilai koefisien determinasi (R2) yaitu sebesar 0,025 artinya 2,5\% kelimpahan makrozoobenthos di pengaruhi oleh bahan organik dan $97,5 \%$ sisanya dipengaruhi oleh faktor lain. Persamaan regresi grafik Perairan Telaga yaituy = $-0,4965 x+34,456$ nilainegatif pada grafik menunjukkan hubungan terbaik yaitu semakin rendah kelimpahan makrozoobenthos maka semakin tinggi kandungan bahan organik, sedangkan persamaan regresi Pulau Bengkoang yaitu $y=1,1545 x+20,881$ nilai positif pada grafik menunjukkan hubungan searah yaitu semakin tinggi kelimpahan maka semakin tinggi kandungan bahan organik. Sesuai dengan pernyataan Ruswahyuni (2010), nilai positif menunjukan hubungan searah ( $x$ naik, maka y naik) dan nilai negative menunjukan hubungan terbalik ( $x$ naik, maka y turun).

Berdasarkan Tabel 2. Suhu di Perairan Telaga yaitu sebesar $30^{\circ} \mathrm{C}$, sedangkan suhu di Pulau Bengkoang yaitu sebesar $32,9^{\circ} \mathrm{C}$. Menurut Ruswahyuni (2010), suhu perairan merupakan salah satu faktor penting dalam metabolisme dan distribusi organisme perairan seperti hewan benthos, baik secara langsung maupun melalui interaksi dengan faktor kualitas air lainnya. Suhu optimal untuk pertumbuhan lamun yaitu antara $23^{\circ} \mathrm{C}-32^{\circ} \mathrm{C}$ (Aji \& Widyastuti, 2020). Semakin tinggi kenaikan suhu perairan, maka semakin sedikit oksigen yang terkandung di dalamnya. Salinitas di Perairan Telaga yaitu sebesar 32 ppt, sedangkan salinitas di Pulau Bengkoang yaitu sebesar 34 ppt. Menurut Ruswahyuni (2010), nilai salinitas optimum yaitu 25 - 35 ppt.

Parameter lingkungan yang menunjukkan Perairan Telaga dan Pulau Bengkoang dikatakan dalam kondisi baik dengan melihat hasil pengukuran DO di Perairan Telaga yaitu sebesar 6,0 $\mathrm{mg} / \mathrm{L}$, sedangkan DO di Pulau Bengkoang yaitu sebesar $6,0 \mathrm{mg} / \mathrm{L}$. Nilai pengukuran $\mathrm{pH}$ di Perairan Telaga yaitu sebesar 7,50, sedangkan $\mathrm{pH}$ di Pulau Bengkoang yaitu sebesar 7,76. Menurut Ruswahyuni (2010), nilai pH optimum untuk perairan yaitu sebesar 6,6-8,5. Organisme bentos menyukai nilai $\mathrm{pH}$ sekitar $7-8,5$ pada lingkungan hidupnya, jika $\mathrm{pH}<7$ maka telah terjadi penurunan populasi terahadap hewan-hewan bentos (Izzah \& Efri, 2016).

Kedalaman Perairan Telaga yaitu sebesar 30-103 cm, sedangkan kedalaman di Pulau Bengkoang yaitu $20-60 \mathrm{~cm}$. Perairan Telaga memiliki perairan yang cukup jernih, sedangkan Pulau Bengkoang memiliki perairan yang sangat jernih sehingga matahari dapat menembus hingga dasar perairan. Tingkat kecerahan perairan dapat menunjukkan sampai sejauh mana penetrasi cahaya matahari menembus kolom perairan. Tingkat kecerahan sangat dipengaruhi oleh kekeruhan perairan, semakin tinggi tingkat kekeruhan perairan, maka akan semakin rendah penetrasi cahaya yang menembus kolom air, sehingga tingkat kecerahan perairan tersrbut semakin rendah (Nuriya, Hidayah \& Syah, 2010). Nilai kecepatan arus di Perairan Telaga yaitu 5-

Tabel 1. Hasil Pengukuran Kualitas Perairan Telaga dan Pulau Bengkoang, Karimunjawa

\begin{tabular}{lcc}
\hline \multicolumn{1}{c}{ Parameter } & Perairan Telaga & Pulau Bengkoang \\
\hline Suhu air $\left({ }^{\circ} \mathrm{C}\right)$ & $30{ }^{\circ} \mathrm{C}$ & $32,9{ }^{\circ} \mathrm{C}$ \\
Salinitas $(\mathrm{ppt})$ & $32 \mathrm{ppt}$ & $34 \mathrm{ppt}$ \\
$\mathrm{DO}(\mathrm{mg} / \mathrm{l})$ & $6,0 \mathrm{mg} / \mathrm{L}$ & $6,0 \mathrm{mg} / \mathrm{L}$ \\
$\mathrm{pH}$ & 7,50 & 7,76 \\
Kedalaman & $30 \mathrm{~cm}-103 \mathrm{~cm}$ & $20 \mathrm{~cm}-60 \mathrm{~cm}$ \\
Arus $(\mathrm{m} / \mathrm{s})$ & $5-20 \mathrm{~cm} / \mathrm{s}$ & $5-20 \mathrm{~cm} / \mathrm{s}$ \\
\hline
\end{tabular}


$25 \mathrm{~cm} / \mathrm{s}$ bergerak ke arah barat, seadangkan nilai kecepatan arus di Pulau Bengkoang yaitu 5-25 $\mathrm{cm} / \mathrm{s}$ bergerak ke arah barat daya sampai barat laut. Arus merupakan faktor fisika yang mempengaruhi kehidupan biota perairan, terutama organisme benthos. Kecepatan arus secara langsung tidak mempengaruhi keberadaan makrozobenthos dan substrat dasar perairan, arus mempengaruhi perpindahan sedimen dan mengikis substrat dasar perairan.

\section{KESIMPULAN}

Kelimpahan makrozoobenthos yang ditemukan di ekosistem padang lamun Perairan Telaga berkisar antara 4-28 ind/ha, sedangkan kelimpahan makrozoobenthos di Pulau Bengkoang berkisar antara 4-32 ind/ha. Nilai kelimpahan makrozoobenthos di Pulau Bengkoang lebihbesar dibandingkan dengan Perairan Telaga.Komposisi bahan organik di Perairan Telaga berkisar antara 2,93-10,34\% dengan kategori sedang. Komposisi bahan organik di Pulau Bengkoang berkisar antara 4,14-40,63\% dengan kategori tinggi. Nilai korelasi kelimpahan makrozoobenthos dengan bahan organik di Perairan Telaga yaitu 0,2352 artinya 23,52\% kelimpahan makrozoobenthos di pengaruhi oleh bahan organik dan 76,48\% sisanya dipengaruhi oleh faktor lain. Hasil korelasi kelimpahan makrozoobenthos dengan bahan organik di Pulau Bengkoang menunjukkan nilai korelasi $r$ sebesar 0,9854 artinya 98,96\% kelimpahan makrozoobenthos di pengaruhi oleh bahan organik dan $1,46 \%$ sisanya dipengaruhi oleh faktor lain.

\section{UCAPAN TERIMAKASIH}

Artikel ini merupakan bagian dari penelitian yang berjudul "Fluktuasi Makrozoobenthos Di Padang Lamun Perairan Telaga Pulau Kemujan dan Pulau Bengkoang, Taman Nasional Karimunjawa." untuk memperoleh gelar Sarjana Strata Satu pada Departemen IImu Kelautan, Fakultas Perikanan dan IImu Kelautan, Universitas Diponegoro, Semarang.

\section{DAFTAR PUSTAKA}

Aji, L.P \& Widyastuti, A. 2020. The Condition And Composition of Seagrass and Mollusca On Biak Island, Papua. IOP Conference Series: Earth and Environmental Science, 404(1):1-14. DOI: 10.1088/1755-1315/404/1/012069

Al-Wedaei, K., et al. 2011. Assemblages of macro-fauna associated with two seagrass beds in Kingdom of Bahrain: Implications for conservation. Journal of the Association of Arab Universities for Basic and Applied Sciences, 10(1):1-7. DOI :10.1016/j.jaubas.2011.06.004

Arami, H. 2019. Komposisi dan Jenis Makrozoobenthos (Infauna) Berdasarkan Ketebalan Substrat Pada Ekosistem Lamun Di Perairan Nambo Sulawesi Tenggara. Jurnal Manajemen Sumber Daya Perairan, 3(4):343-352.

Asriani, N., et al. 2019. Macrozoobenthos community structure in restored seagrass, natural seagrass and seagrassless areas around Badi Island, Indonesia. In IOP Conference Series: Earth and Environmental Science, 253(1):12-34. DOI: 10.1088/1755-1315/253/1/012034

Effrosynidis, A.D., Arampatzis, A. \& Sylaios, G. 2019. Seagrass And Hydrographic Data For The Mediterranean Sea. Data in Brief. 25:1-8. DOI: 10.1016/j.dib.2019.104286

Indrawan, G.S., Yusup, D.S., \& Ulinuha, D. 2016. Asosiasi Makrozoobentos Pada Padang Lamun di Pantai Merta Segara Sanur, Bali. Jurnal Biologi Udayana, 20(1):11-16. DOI: 10.24843/JBIOUNUD.2016.v20.i01.p03

Izzah, N.A \& Eferi, R. 2016. Keanekaragaman Makrozoobenthos di Pesisir Desa Panggung Kecamatan Kedung Kabupaten Jepara. Bioeksperimen: Jurnal Penelitian Biologi, 2(2):140148. DOI: 10.23917/bioeksperimen.v2i2.2492.

Muliawan, R., Irma, D., \& Sofyatuddin, K. 2016. Struktur Komunitas Makrozoobenthos dan Kondisi Substrat Pada Kawasan Mangrove Di Pesisir Pulau Weh. Jurnal IImiah Mahasiswa Kelautan dan Perikanan Unsyiah. 2(2):297-306. DOI : 10.21107/rekayasa.v11i1.4125

Nuriya, H., Hidayah, Z \& Syah, A. F. 2010. Analisis Parrameter Fisika Kimia di Perairan Sumenep Bagian Timur dengan Menggunakan Citra Landsat TM5. Jurnal Kelautan : 
Indonesian Journal of Marine Science and Technology, 3(2):132-138. DOI : 10.21107/jk.v3 i2.922

Rachman, H., Priyono, A., \& Mardianto, Y. 2016. Makrozoobenthos sebagai Bioindikator Kualitas Air Sungai di Sub DAS Ciliwung Hulu. Media Konservasi, 21(3):261-269. DOI : 10.29243/medkon.21.3.261-269

Ristianti, N. 2014. Hubungan Kelimpahan Epifauna Pada Kerapatan Lamun Yang Berbeda Di Pantai Pancuran Belakang Pulau Karimunjawa, Jepara. Management of Aquatic Resources Journal, 3(4):34-40. DOI: 10.20473/jipk.v2i1.11676

Ruswahyuni, R. 2010. Populasi dan Keanekaragaman Hewan Makrobenthos Pada Perairan Tertutup dan Terbuka Di Teluk Awur, Jepara [Macro Benthic Animal Population and Biodiversity In Closed And Open Waters In The Awur Bay, Jepara]. Jurnal IImiah Perikanan dan Kelautan, 2(1):11-20. DOI: 10.20473/jipk.v2i1.11676

Tussa'diyyah, H., Purwoko, A., \& Kamal, M. 2018. Keanekaragaman Makrozoobentos di Sungai Musi Desa Sungsang Kabupaten Banyuasin, Sumatera Selatan. Jurnal Penelitian Sains, 20(2):63-69. DOI: 10.36706/jps.v20i2.510

Warzocha, J., Gromisz, S., Wodzinowski, T. \& Szymanek, L., 2018. The structure of macrozoobenthic communities as an environmental status indicator in the Gulf of Gdańsk (the Outer Puck Bay). Oceanologia, 60(4):553-559. DOI: 10.1016/j.oceano.2018.05.002 